\author{
Bartosz Radzymiński, Jarosław Goszczak \\ Lodz University of Technology, Mechanical Department, Department of Vehicles and Fundamentals of \\ Machine Design \\ 116 Żeromskiego street, 90-924 Lodz, bartosz.radzyminski@p.lodz.pl, jaroslaw.goszczak@p.lodz.pl
}

\title{
VERIFICATION OF A METHOD FOR DETERMINING THE LIMIT PRESSURE PEAK IN A MECHANICAL CONTINUOUSLY VARIABLE TRANSMISSION
}

\begin{abstract}
This research concerns the continuously variable transmission that is to be used in a hybrid drivetrain with a mechanical energy accumulator as a secondary energy source. The purpose of this research is to verify the method of determining the pressure surge which ensures a fast but safe ratio change, from the perspective of the belt slip point of a continuously variable transmission.
\end{abstract}

The obtained results allowed to decide on the design of a more extensive test bench enabling simulation of the load of a continuously variable transmission resulting from the acceleration and braking of the car's mass. In addition, the test results confirmed the possibility of regulating the pressures in two actuators to change the ratio and increase the speed of this change.

\section{Key words}

CVT, chain slip, dynamics, fuel save, hybrid drivetrain

\section{Introduction}

The upcoming environmental regulations concerning the reduction of emissions of harmful compounds contained in exhaust gases, enhance the popularity of stepless transmissions used for drive systems of passenger cars. Such a solution can also be transferred to a reduction in fuel consumption due to the possibility of operating an internal combustion engine in its optimal range due to applying the control strategy required at a given moment.

One of the ideas to meet the requirements is alternative vehicle powertrain hybridization using hybrid pneumatic powertrain. This kind of solution can be found in [1]. Another idea is using compressed air as an innovative solution for hybridization for small gasoline engine. The combination of a conventional IC engine and a pneumatic short-term storage system to achieve lower fuel consumption is described in [2]. Currently most popular solution for hybrid vehicles is hybrid electric vehicle. Electric storage in high voltage batteries with technical, economic and environmental impacts assessments is described in [3] and [4].

Another idea how to increase the overall efficiency of the drive system is to use an additional (secondary) energy source that could replace the internal combustion engine during its worst-performing periods and which would be able to accumulate lost energy for later delivery while decelerating the vehicle. Such ideas are realized by hybrid propulsion systems combined in different configurations of the primary energy source, which is most often an internal combustion engine with a secondary energy source. Electric batteries that cooperate with motors and power generators are the most frequently used secondary source of energy by car manufacturers. (More information about configurations of hybrid drive systems can be found in [5].) Regardless of the type of secondary energy source, each configuration of a hybrid system should ensure compensation of weaknesses of one source with the advantages of the other. Thanks to this, it is possible to enable both energy sources to work specifically in the areas of their greatest efficiency.

An interesting, much less complicated and cheaper alternative solution is a mechanical energy accumulator. In drive systems using electric machines, the stepless module can consist of a planetary gear (e-CVT). The most rational drive system with a mechanical energy accumulator use a mechanical continuously variable transmission. The same transmission, in mode of operation with an internal combustion engine, can serve as a gearbox. In this solution, a high speed and precise ratio change of the continuously variable transmission is required throughout its entire range. 
The two main advantages of hybrid drivetrain systems are the reduction of pollutants contained in exhaust gases and reduced fuel consumption.

Another very important advantage of hybrid drivetrains equipped with a steel flywheel is that their production and recycling is cheaper and more environmentally friendly than using electric energy accumulators.

\section{Review of solutions for hybrid drive systems}

In most advertising materials, manufacturers write about the kinetic energy recovery system (KERS). In principle, each hybrid propulsion system should allow for the recovery of a car's kinetic energy during braking, however, in order to comply with the manufacturers' names, the terminology used has been preserved.

There are many solutions for hybrid drive systems. Currently, offers of hybrid car manufacturers are mainly focused on electric hybrid vehicles (HEV). Some of these have the option of recharging the battery from an external power source (plug-in hybrid electric vehicle - PHEV). The other solutions described below were used in motor sports or remained in the prototype phase.

- Hybrid Electric Vehicle by Toyota [6]

The system is composed of the electric motor, the engine, the battery, the generator, the power split device and the power control unit (inverter/boost converter/DC/DC converter). The power split device transfers part of the power produced by the engine to drive the wheels, and the rest to the generator to either provide electric power for the motors or to recharge the battery.

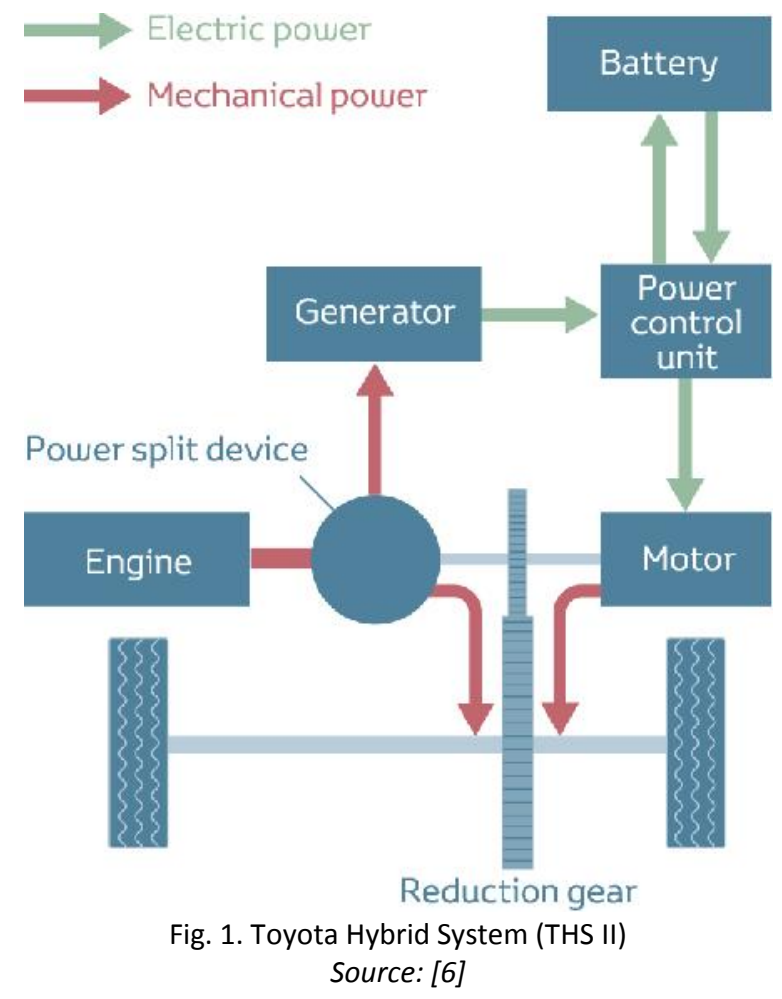

- $\quad$ Electric KERS [7]

In this solution, the electric machine is connected to the crankshaft of the engine. When braking the vehicle, part of the torque is transferred to this electric machine (operating as a power generator) that converts the vehicle's kinetic energy into electricity which is stored in batteries. During the use of stored energy, the batteries supply the electric machine which then operates in the electric motor mode and is able to transmit up to $63 \mathrm{~kW}$ of power. 


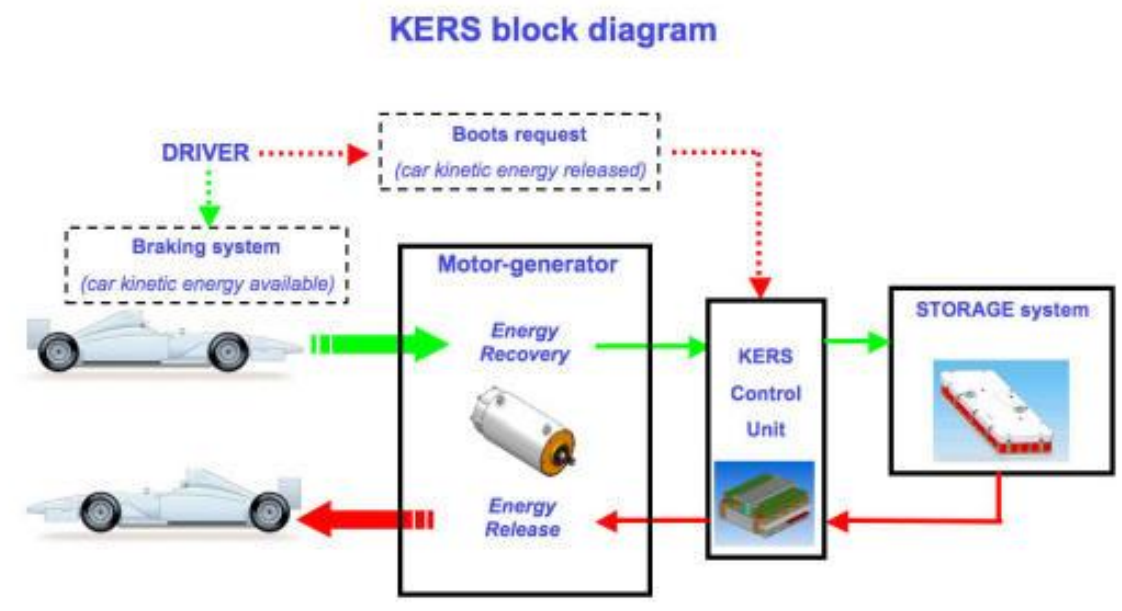

Fig. 2. Electric KERS - a solution by Magneti Marelli
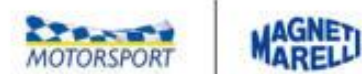

Source: [7]

- Electro-mechanical KERS - Williams solution [8]

The idea behind this solution is the generation of electricity during the vehicle's braking by using electric machines operating at the moment of braking as current generators (60kW each) by being connected to the wheels of the front axle. This energy is then used to accelerate the flywheel up to 40,000 rpm, which also serves simultaneously as the rotor of the second electric machine which works at that time as an electric motor. When the demand for additional drive force arises, the roles of the two electric machines are reversed. Stored by the rotating flywheel (the rotor of the second electric machine), the energy is converted into electric energy generated by the second electric machine operating as a power generator. Then this energy goes to electrical motors connected to the front wheels.

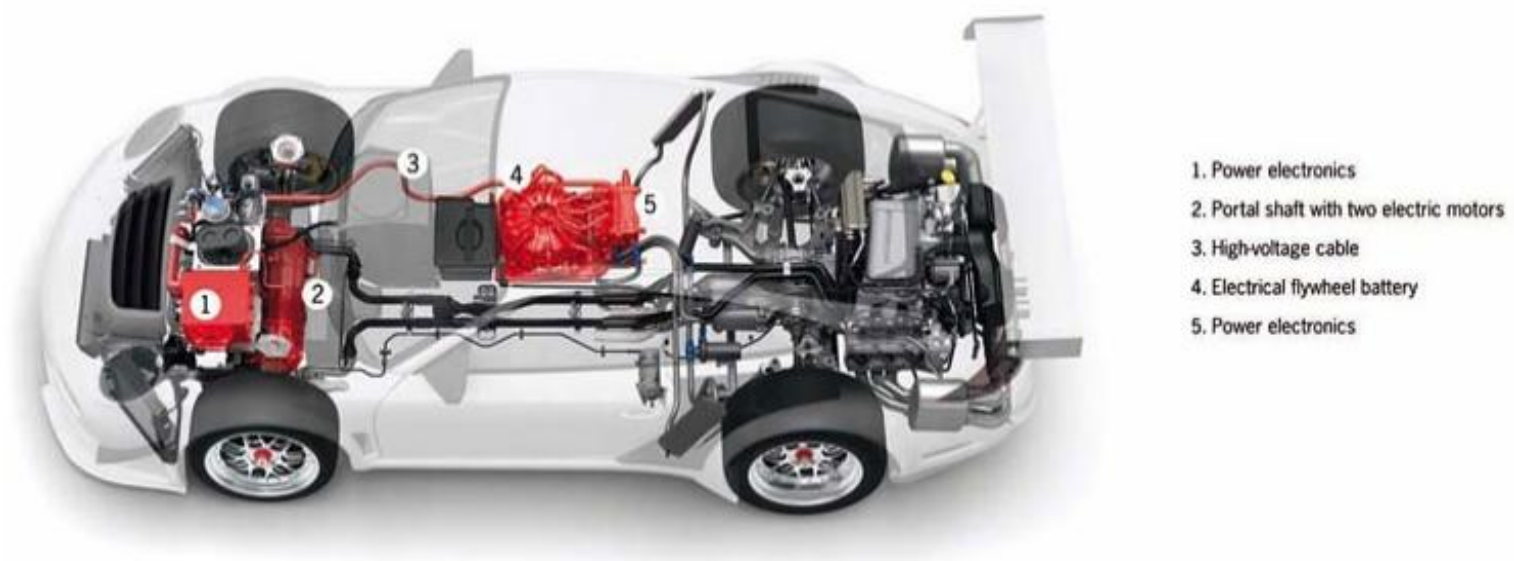

Fig. 3. Diagram of the electro-mechanical KERS system Source: [8]

- Mechanical KERS - Flybrid solution (Torotrak Group) [9]

In this solution, the original drive source through the conventional drive system is connected to the wheels of the front axle. The secondary energy source (carbon fiber flywheel weighing $6 \mathrm{~kg}$ ) during braking of the vehicle is driven from the rear wheels by a mechanical toroidal variable speed transmission which can even reach $60,000 \mathrm{rpm}$. Then, to transfer the accumulated energy to the wheels, the variable transmission changes the ratio in such a way as to reduce its speed so that the flywheel accelerates the car's wheels. 


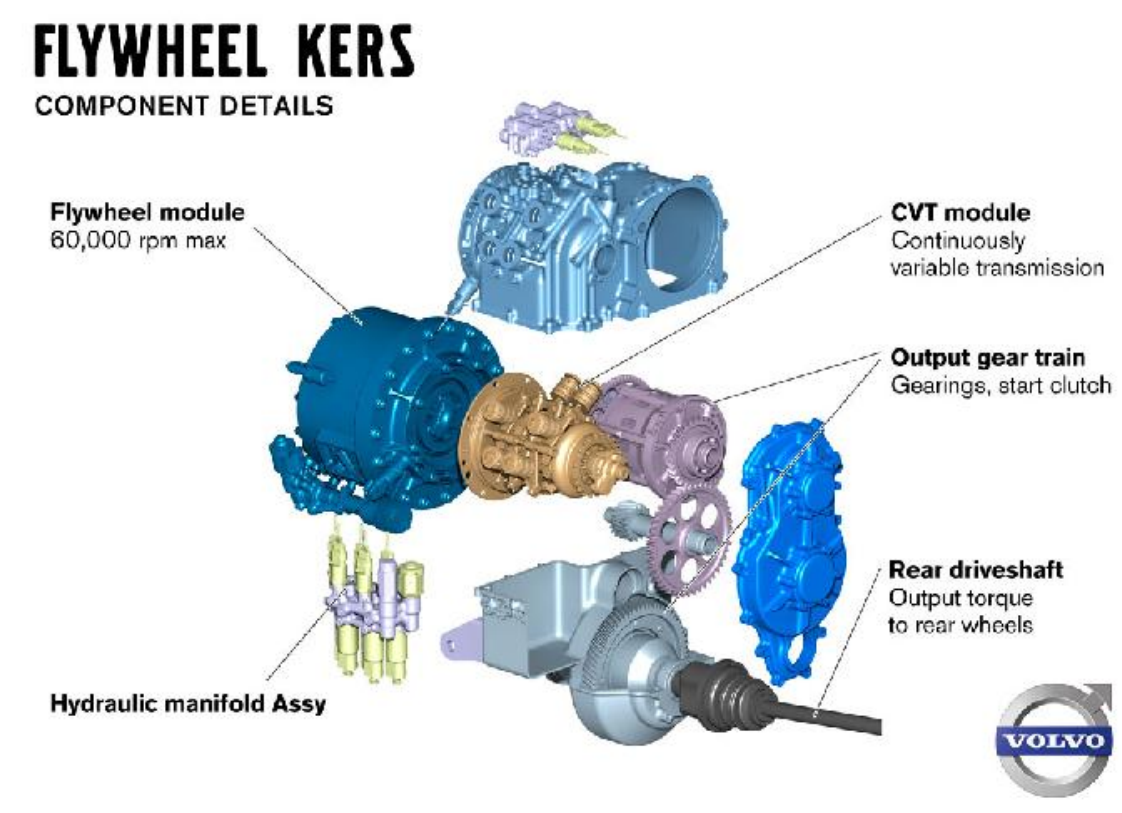

Fig. 4. Diagram of the mechanical KERS system Source: [9]

This system was the only one designed for a passenger car intended for use in traffic. The manufacturer claims that urban traffic allows it to reduce fuel consumption by up to $25 \%$, and according to the new European cycle, while driving the engine will be shut down for about $50 \%$ of the time.

\section{Mechanical continuously variable transmission}

The most popular type of mechanical continuously variable transmission uses a metal belt or chain. It works with two pulleys, each consisting of two cones. Moving one cone away reduces the wrap radius. At the same time a cone is moved on the second wheel to maintain constant chain or belt tension. The change in diameters changes the ratio.

Each of the mentioned solutions has devices that act as a stepless module. This can be in the form of a properly connected planetary gear, an inverter that controls the operation of electric motors and generators or a mechanical continuously variable transmission.

Low ratio

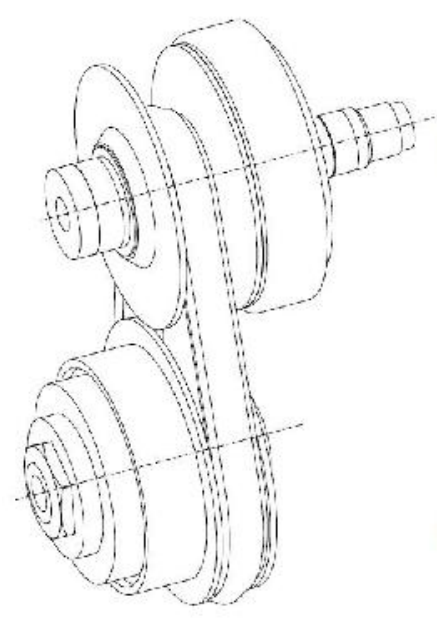

Overdrive ratio

Energy source side

Drive wheels side

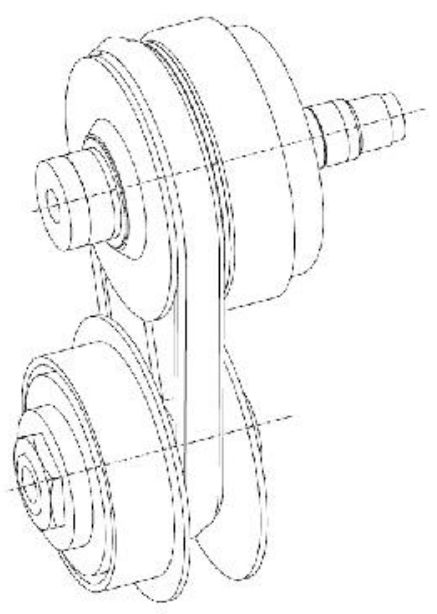

Fig. 5. Mechanical belt/chain continuously variable transmission

Source: Author's 


\section{Prototype hybrid drivetrain}

The purpose of this research was to verify the method of determining the pressure surge which ensures a fast but safe ratio change, from the perspective of the belt slip point of a continuously variable transmission.

Designed mechanical energy accumulator should allow to accumulate energy allowing to achieve speed of $50 \mathrm{~km} / \mathrm{h}$ by $1000 \mathrm{~kg}$ car without using internal combustion engine.

The proposed prototype hybrid drive system assumes the use of a mechanical continuously variable transmission using the LuK chain. This transmission acts as a gearbox when using the primary energy source and as a stepless module connecting the mechanical energy accumulator with the drive wheels of the car.

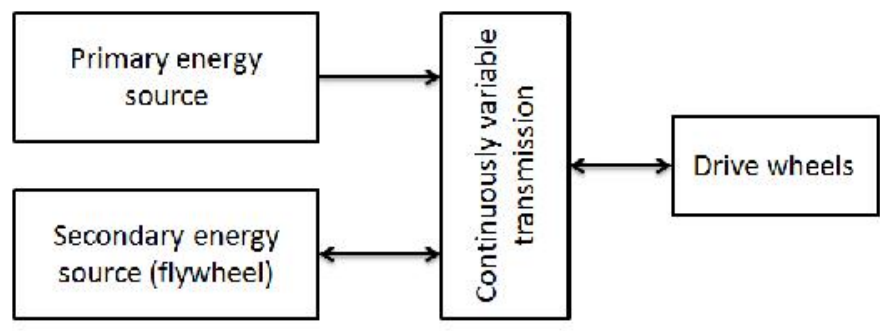

Fig. 6 . The general scheme of the prototype hybrid drive system Source: Author's

The purpose of using a mechanical energy accumulator is to accumulate the kinetic energy of the decelerating vehicle in order to use it during acceleration. When decelerating the vehicle the energy must be transferred from the diminishing speed of the car to an ever faster-spinning flywheel. The necessity of changing the ratio between the wheels of the vehicle and the flywheel follows in a continuous manner. This is similar when accelerating the vehicle. The process of charging and discharging the mechanical accumulator requires the transmission to change ratio continuously during the braking or acceleration of the car, which is significantly shorter than the ratio change required by a stepless conventional drive system. The function of the stepless change is fulfilled by sliding conical discs coupled with a chain. The displacement of the discs is carried out by hydraulic cylinders with the same areas. Correct flow and oil pressure in the cylinders are to ensure the specified ratio and chain tension sufficient to transfer the torque. This tension must ensure that the chain does not slip excessively, but it should not be too large so as to increase the mechanical losses of the transmission. More information about slip control can be found in [10].

In a situation in which the pressure P1 and P2 are constant, the ratio is fixed and there is no chain slip, the change of any of the pressures will change the ratio and change the chain tension force. In the prototype transmission, the stops of the mechanical stoppers of the conical wheels were placed on a pulley located on the side of the energy source. For this reason, the secondary pulley is treated as responsible for the belt tension because this wheel will not lean against the mechanical limiter and will be affected by the force resulting from the oil pressure. Consequently, the input pulley is generally considered to be responsible for the transition. For this reason, in the tests of the continuously variable transmissions, the pressure P2 is most often set constant, changing the ratio by pressure P1 [11].

In the situation of starting from the set operating conditions, to change the ratio at constant pressure $\mathrm{P} 2$, the pressure P1 should be changed. The greater the pressure change will be, the faster the change speed will be. The problem is the situation when pressure P1 is close to the extreme, the difference between initial and set pressure which determine ratio speed change is limited. In this case, stability of P2 pressure can be dispensed and this pressure used to change the ratio. This situation is shown in Figure 7. 

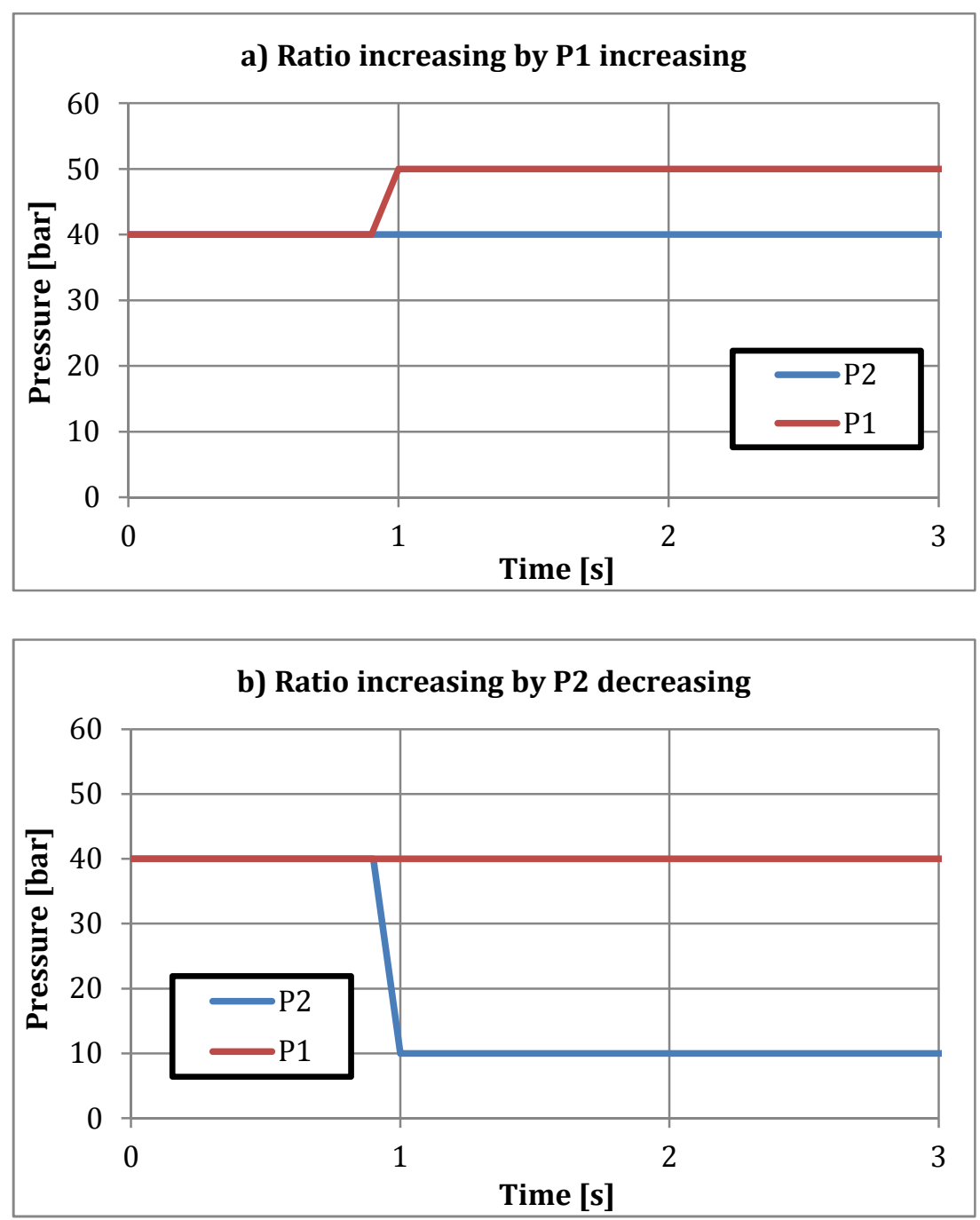

Fig. 7. Increasing the ratio by a) increasing P1; b) decreasing P2 Source: Author's

In the situation presented in diagram $7 b$ ), the pressure difference that can be obtained in relation to the steady state, causing the ratio to increase is much higher (30bar) than in the situation shown in diagram 7a), where the pressure difference with respect to the steady state is much lower (10bar). It follows from the above that in such a case the terms "constant pressure actuator" and "variable pressure actuator" should not be assigned to specific actuators. However, a problem arises as to how to prevent the chain from slipping. The difficulty in determining the analytical equation providing the required chain pressure in transient states showed the necessity to perform tests at the test bench enabling simulation of the inertia of a car. Such a test bench is under construction, and for the purpose of preliminary research, initial tests were carried out on the existing test bench. Different control problems are described in [12].

\section{Load of continuously variable transmission}

The load of the continuously variable transmission during cooperation with the secondary energy source in the prototype hybrid drive system results from the energy exchange between the car and the mechanical energy accumulator. During energy recuperation, the torque loading the transmission results from increasing the flywheel rotational speed at the expense of reducing the speed of the car. In the return process when force is accumulated in the energy wheel, the load on the transmission results from the increase of the speed of the car at the expense of reducing the rotational speed of the flywheel. These phenomena result from the second principle of Newton's dynamics. Allowing the chain to slip causes damage to the pulleys and chain which can lead to difficulties in setting and maintaining the set ratio. 


\section{Test bench}

Figure 8 shows the diagram of mechanical, hydraulic and electrical connections located on the test bench.

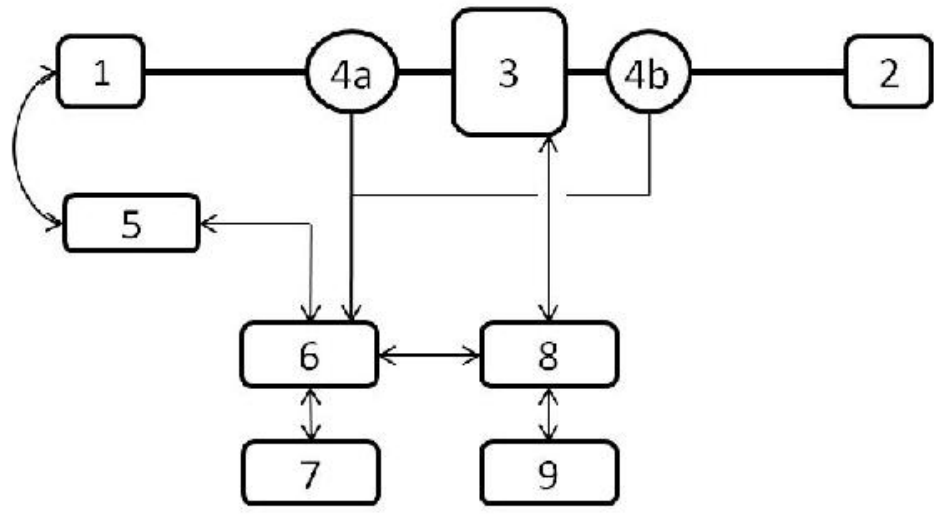

Fig. 8. Scheme of the test bench: 1-electric motor; 2 -inertia; 3-continuously variable transmission; 4a, 4b-torquemeters; 5inverter; 6-ECU; 7-operator interface; 8-hydraulic blocks; 9-hydraulic group

Source: Author's

An electric machine (motor) (1) was used to drive the tested variable transmission (3). By using the inverter (5) it was possible to smoothly control the engine speed in a range of $\pm 3000 \mathrm{rpm}$. (More information about the electric motor control system used in the test bench can be found in [10].) The load element of the transmission was a rotating mass (2) with moment of inertia I $=0.6 \mathrm{kgm} 2$. Two torque gauges ( $4 \mathrm{a}$ and $4 \mathrm{~b}$ ) were used to measure the torque at the input and output of the tested transmission. For lubrication and for controlling the pressures in the pulley cylinders an external hydraulic group (9) was used with the drive source independent of the work of the tested object. This group supplied hydraulic blocks (control with preliminary pressure [13]) (8) enabling a smooth change of pressure (and thus a change in transmission ratio and belt/chain tension. This system worked in a closed loop of pressure control. Using the user interface (7), the operator controlled the control platform (6). Thanks to this, it was possible to set and read data.

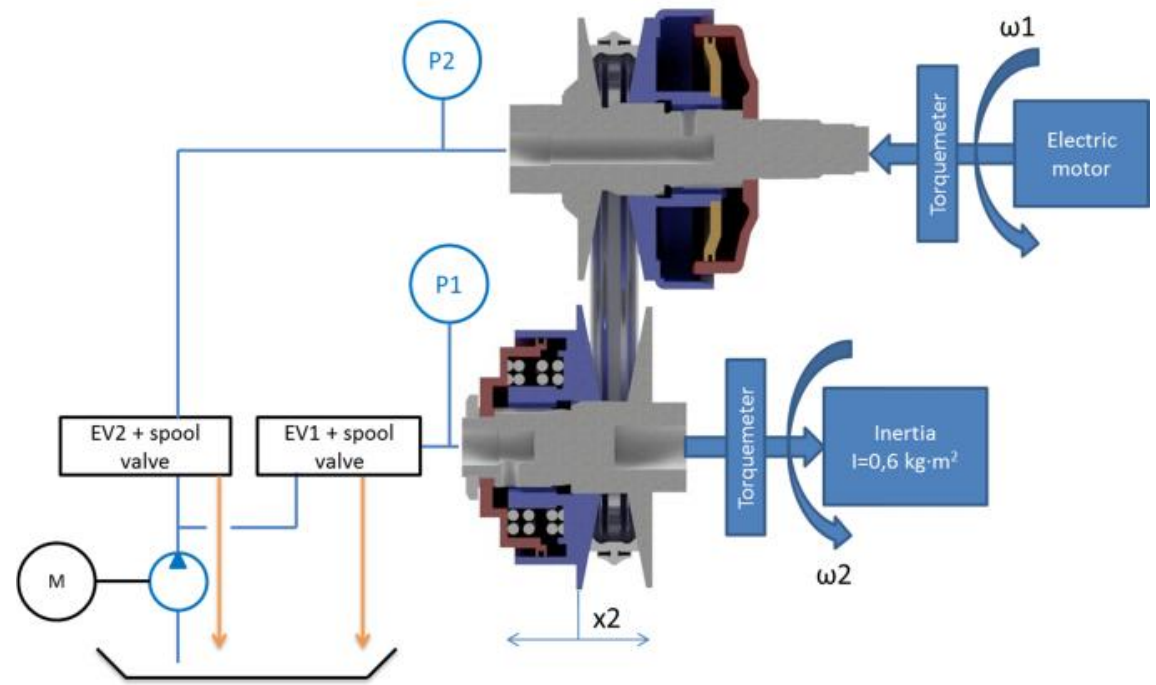

Fig. 9. Diagram of connection of the tested transmission to the hydraulic system and the drive and braking unit Source: Author's

During the tests, the electric machine was controlled in the rotational speed mode, set at a constant value of

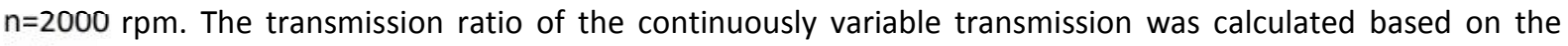
indication of the speed sensors of the rotating pulleys as the quotient of the rotational speed of the output pulley and the input pulley:

$I_{c v t}=\frac{\omega_{2}}{\omega_{1}}$.

In addition, during the tests, the position of the moving cone of the output pulley was checked, which was converted into a ratio resulting from the radius of the belt. Comparison of these two ratios allowed for the occurrence of chain slip. 


\section{Research}

The aim of the conducted research was to check the methodology for determining the maximum possible speed of transmission shifting of a continuously variable transmission linked to hybrid drive system's road wheels with a mechanical energy accumulator. This consisted of establishing one pressure at a constant level and setting the second pressure with a value ensuring the given ratio and causing a sudden change in that pressure. A given series of measurements started with small changes in pressure and ended at the time when symptoms appeared indicating slip occurrence. The first attempts were to establish the pressure in the secondary pulley actuator - P2.

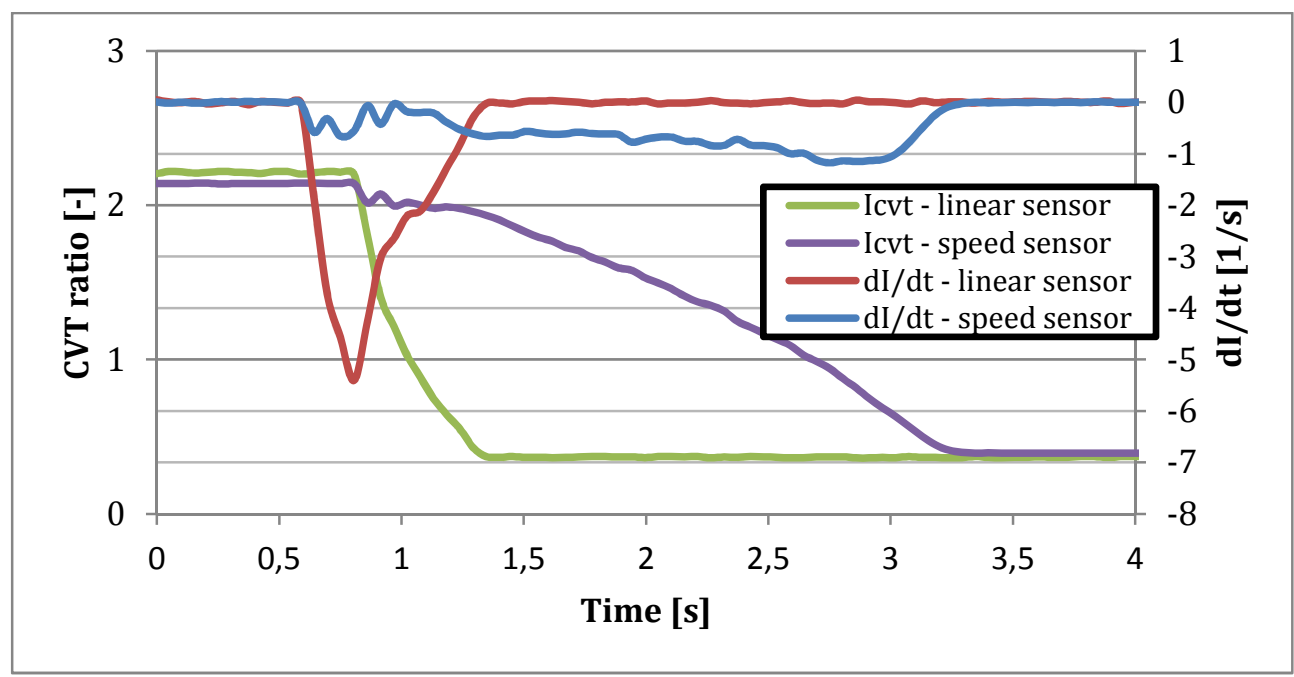

Fig. 10. Sample result from a constant P2 pressure test Source: Author's

Figure 10 shows sample results from a constant pressure test $\mathrm{P} 2=35 \mathrm{bar}$. For a given jump $\Delta \mathrm{P} 1=17 \mathrm{bar}$ there was a slip of the belt - this is indicated by a different course of the ratio curve resulting from the position of the cone wheel than the ratio curve calculated from the pulleys speed sensors and the accompanying metallic noise coming from the tested body. Subsequent tests assumed maintaining constant pressure in the primary pulley cylinder.

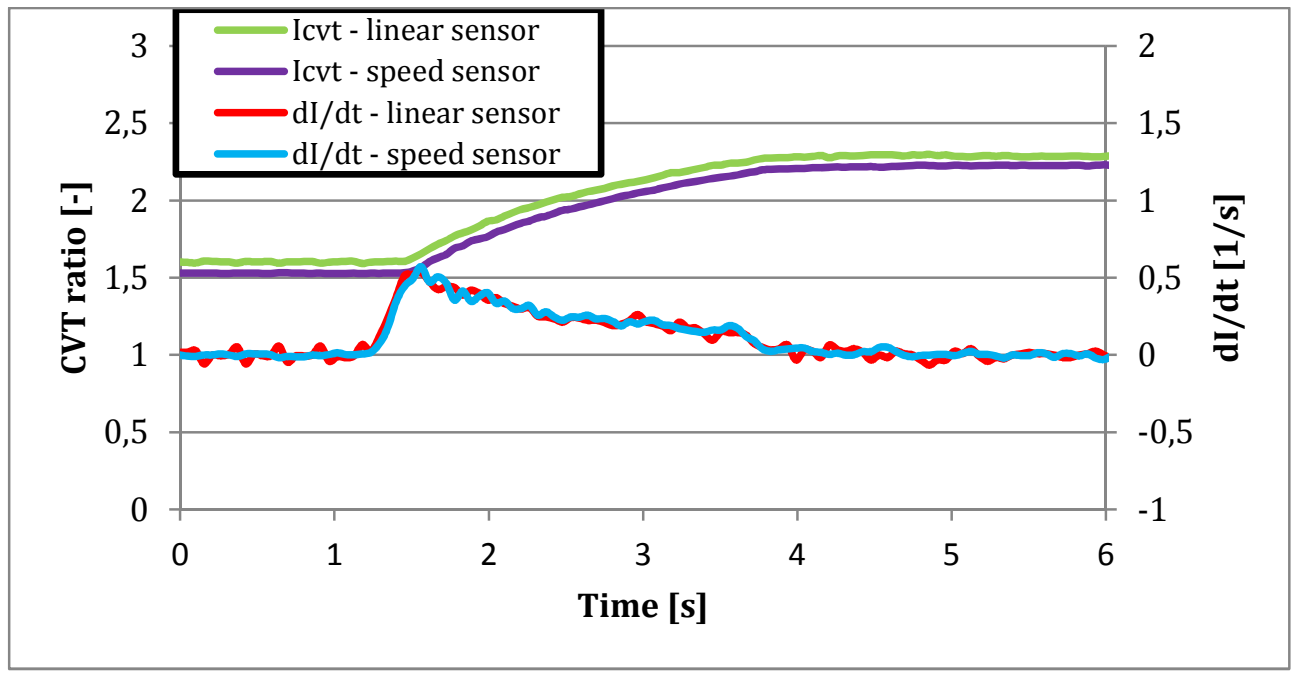

Fig. 11. Sample result from a constant P1 pressure test Source: Author's

Figure 11 shows an example of the results from a test performed at a constant pressure of P1 = 35bar. In this case, the coverage of the ratio curves indicates the absence of chain slip ( $\triangle \mathrm{P} 2=10 \mathrm{bar}$ ). 


\section{Results}

Figure 12 shows limit values of pressure changes that cause ratio change without the risk of chain slippage that could damage the transmission.

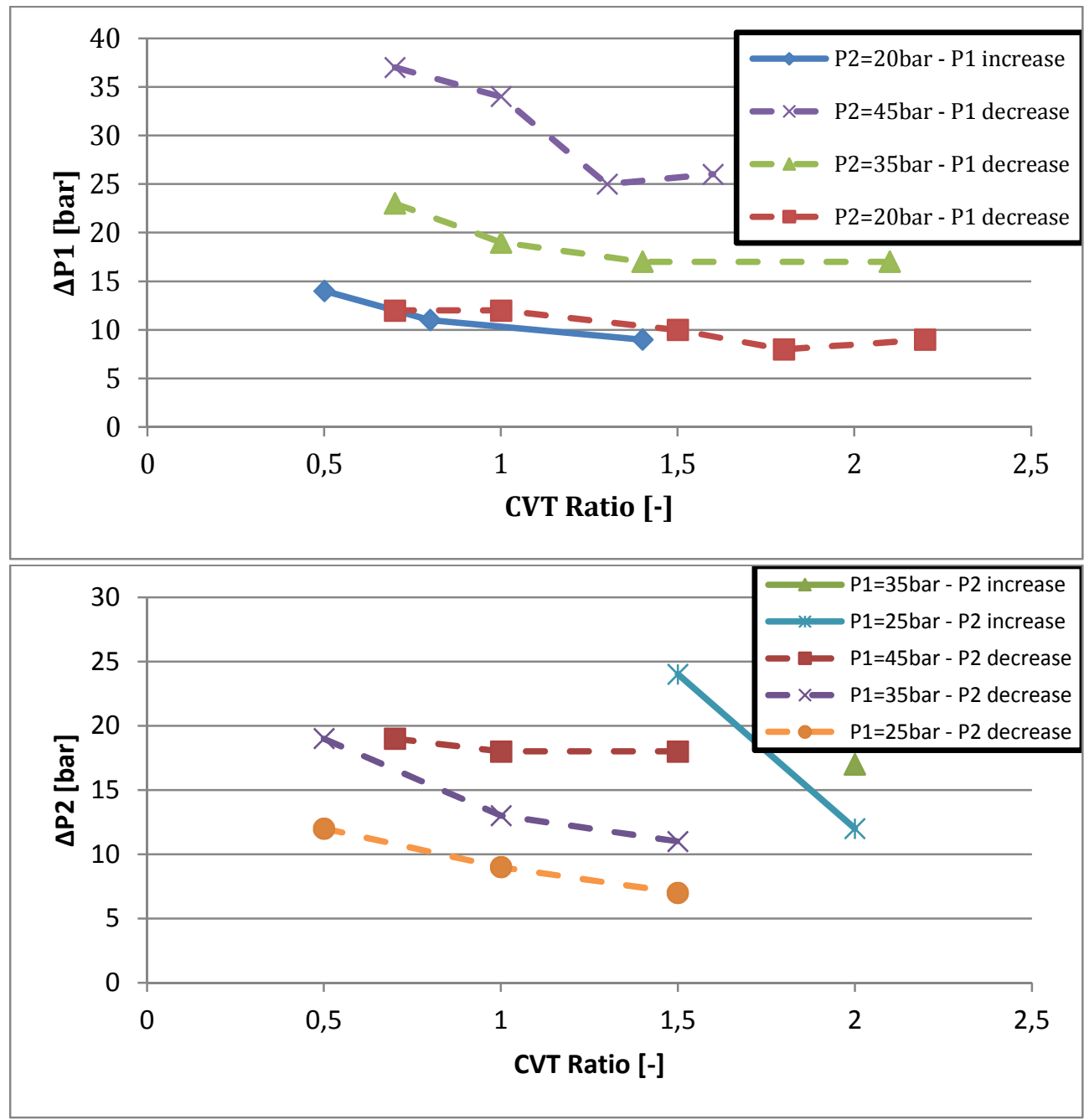

Fig. 12. Limit $\Delta \mathrm{P} 1$ and $\Delta \mathrm{P} 2$ values ensuring no chain slip Source: Author's

For pressures $\mathrm{P} 2=35 \mathrm{bar}$ and $\mathrm{P} 2=45 \mathrm{bar}$, during the $\mathrm{P} 1$ pressure increase (increase of the ratio), excessive chain slip was not present, so for this case limit values of $\Delta \mathrm{P} 1$ are 9-15bar for $\mathrm{P} 1$ increasing and 9-36bar for P1 decreasing. Higher $\Delta \mathrm{P} 1$ values correspond to higher $\mathrm{P} 2$ values. Only at pressure $\mathrm{P} 1=20$ bar there were chain slip. This is due to the large difference in pressure possible to achieve. For pressure P1 = 45bar, no occurrence of slip was noticed when increasing pressure P2.

\section{Summary and conclusions}

The tests clearly indicated that a greater pressure jump in relation to its steady state value translates into a higher rate of shifting. However, this does not mean that in each case the pressure can be increased or decreased in steps up to the extreme values ( 0 or 50bar) as this may lead to chain slip. The solution to this problem could be simultaneous control of both P1 and P2 pressure. The introduction of such a solution would require the implementation of a complicated algorithm that would take in account the dynamic changes in chain contact and radii. The performed tests confirmed the correctness of the test methodology, which will be carried out on a test stand which will enable simulation of the load of the variable transmission resulting from braking and acceleration of both the car and the mechanical energy accumulator. This test bench is currently being built at the Department of Vehicles and Machine Building Basics of the Lodz University of Technology. 
Higher drive comfort, reduction of harmful emission compounds contained in exhaust gases and reduction of fuel consumption are compelling reasons for the search for newer and more advanced solutions in the field of hybrid vehicles.

\section{Acknowledgements}

The authors would like to thank prof. Zbigniew Pawelski and dr. Andrzej Werner for substantive help that was provided during the researches and for making the first adjustments of text before sending it for publication.

\section{References}

[1] Z. Dimitrova, P Lourdais, F. Maréchal, Performance and economic optimization of an organic rankine cycle for a gasoline hybrid pneumatic powertrain, Energy 86 (2015) 574-588.

[2] ] Z. Dimitrova, F. Maréchal, Gasoline hybrid pneumatic engine for efficient vehicle powertrain hybridization, Applied Energy 151 (2015) 168-177.

[3] Z. Dimitrova, F. Maréchal, Environomic design of vehicle energy systems for optimal mobility service, Energy 76 (2014) 1019-1028.

[4] Z. Dimitrova, F. Maréchal, Techno-economic design of hybrid electric vehicles and possibilities of the multiobjective optimization structure, Applied Energy 161 (2016) 746-759.

[5] BOSCH, Napędy hybrydowe, ogniwa paliwowe i paliwa alternatywne (hybrid drives, fuel cells and alternative fuel), Wydawnictwa Komunikacji i Łączności, Warszawa, 2010.

[6] http://www.toyota-global.com/innovation/environmental_technology/technology_file/hybrid/ hybridsystem.html access 1.05 .2018

[7] http://www.racecar-engineering.com/articles/f1/kers-in-f1-how-kers-will-change-formula-one-in-2011/ access 1.05.2018

[8] http://www.greencarcongress.com/2010/02/gt3r-20100211.html access 1.05.2018

[9] https://www.autoevolution.com/news/torotrak-to-supply-parts-for-volvo-s-flywheel-kers-35977.html access 1.05.2018

[10] Z. Pawelski, Falowniki $A B B+$ moc krążąca = oszczędność energii na stanowisku badawczym (ABB + circulating power = energy saving on a test bench), Napędy i Sterowanie, 4 (2005) 14-16.

[11] B. Radzymiński, J. Goszczak, Generating the pressure to control the gear ratio of a continuously variable transmission in car, The Archives of Automotive Engineering, 74 (2016) 95-104.

[12] B. Radzymiński, Some control problems of continuously variable belt transmission, IOP Conference Series: Materials Science and Engineering, 148 (2016) 012049.

[13] BOSCH, Elektroniczne sterowanie skrzynką biegów EGS (Electronic control of the EGS gearbox), Wydawnictwa Komunikacji i Łączności, Warszawa, 2005. 